\title{
Does Localisation of Fracture Line, According to Epicondyles, Affect Ligamentotaxis Negatively in Displaced Pediatric Supracondylar Humerus Fractures?
}

\author{
Ali Yuce ${ }^{1}$, Cem Dincay Buyukkurt ${ }^{2}$, Bulent Karslioglu², Ahmet Oncul' ${ }^{3}$, Mustafa Yerli ${ }^{2}$ and Hakan Gurbuz ${ }^{2}$ \\ ${ }^{1}$ Department of Orthopedic and Traumatology, Başakşehir Pine And Sakura City Hospital, Istanbul, Turkey \\ ${ }^{2}$ Department of Orthopedic and Traumatology, Prof. Dr. Cemil Taşcioğlu City Hospital, Istanbul, Turkey \\ ${ }^{3}$ Department of Orthopedic and Traumatology, Ege University, Izmir, Turkey
}

\begin{abstract}
Objective: To investigate the effect of localisation of the fracture line according to the trans-epicondylar line on open reduction rates and postoperative reduction quality.

Study Design: Observational study.

Place and Duration of Study: Department of Orthopedic and Traumatology, Prof. Dr. Cemil Taşcıoğlu City Hospital, İstanbul, Turkey, from January 2011 to December 2018.

Methodology: Pediatric cases (37 females-54 males) which underwent surgery with Gartland type three supracondylar humerus fracture having extension deformity, were included and examined retrospectively. Localisation of fracture line according to trans-epicondylar line, presence of postoperative rotation, sagittal and coronal deformity, reduction type and surgery duration were noted.

Results: According to trans-epicondylar level, fracture line passed through upper level of the line in 68 cases, while it passed through lower level in 23 cases. Rotation rate of patients, whose fraction line localisation was lower according to trans-epicondylar level $(60.87 \%)$, was higher than upper localization patients $(8.82 \%, p<0.001)$. It has been observed that the relation between localisation of fracture line according to trans-epicondylar level and sagittal deformity, coronal deformity, reduction type and surgery durations were similar $(p>0.05)$.
\end{abstract}

Conclusion: Determination of localisation of fracture line according to trans-epicondylar level in preoperative roentgenograms may allow the surgeon to predict the possibility of postoperative rotation deformity.

Key Words: Fracture line, Humerus, Supracondylar, Pediatric, Epicondyle.

How to cite this article: Yuce A, Buyukkurt CD, Karslioglu B, Oncul A, Yerli M, Gurbuz H. Does Localisation of Fracture Line, According to Epicondyles, Affect Ligamentotaxis Negatively in Displaced Pediatric Supracondylar Humerus Fractures?. J Coll Physicians Surg Pak 2021; 31(01):45-50.

\section{INTRODUCTION}

Supracondylar humerus fractures (SHF) are common elbow injuries that comprise of $16 \%$ of all pediatric fractures and two-thirds of all hospitalisations for pediatric elbow injuries. ${ }^{1,2}$ Ninety-eight percent of these cases are extension type injuries. ${ }^{3}$ The ideal treatment for children with Gartland Type III SHF is closed reduction and stable percutaneous fixation with Kirschner wires. ${ }^{3}$ Thepurpose of the traditional method is to adapt the distal fragment to the proximal fragment. Closed reduction may fail in a small number of cases (with a rate ranging between $3 \%$ and $46 \%$ ). Insufficient reduction during fixation or loss of primary reduction may cause cubitus varus deformity or loss of elbow flexion. ${ }^{4}$

Correspondence to: Dr. Mustafa Yerli, Department of Orthopedic and Traumatology, Prof. Dr. Cemil Taşcioğlu City Hospital, Istanbul, Turkey

E-mail: mustafayerli199@gmail.com

Received: September 22, 2020; Revised: December 18, 2020;

Accepted: December 28, 2020

DOI: https://doi.org/10.29271/jcpsp.2021.01.45
Considering the mechanism of these fracture, fracture formation is expected to occur in the area where the olecranon with hyperextension of the elbow, and the olecranon fossa where the humerus is narrowed is pressed on the thin cortical bone. ${ }^{5} \mathrm{Elbow}$ joint anatomically include joint capsule, olecranon, coronoid fossa, and radial fossa. However, it does not include humeral epicondyles. Medial collateral ligament (MCL) sticks to medial epicondyle, while lateral collateral ligament (LCL) sticks to lateral epicondyle. ${ }^{6}$

Ligamentotaxis is the principle of molding fracture fragments into alignment as a result of tension applied across a fracture by the surrounding intact soft tissues. LCL and MCL have an important role in closed reduction of pediatric supracondylar humerus fractures by ligamentotaxis. ${ }^{7,8}$ The hypothesis was that for these fractures, one or both sides of the fracture line remaining below the epicondylar level will impair ligamentotaxis during closed reduction. In cases where the fracture level is localised in the distal of the epicondyles, an increase may be observed in open reduction ratesor postoperativecoronal/sagittal/axial deformity rates after reduction. 
For these reasons, the aim of the study was to investigate the effect of localisation of the fracture line according to the designed trans-epicondylar line (TEL) on open reduction rates and postoperative reduction quality.

\section{METHODOLOGY}

Files of 187 patients, operated due to pediatric SHF at Orthopedics and Traumatology Clinic of the Department of Orthopedic and Traumatology, Prof. Dr. Cemil Taşcıoğlu City Hospital, İstanbul, Turkey, from January 2011 to December 2018, were examinedretrospectively. Ninety-onepediatric cases whounderwent surgery with close SHF having extension deformity of either gender presenting within 24 hours of injury, were included in the study. Patients whose surgical intervention time exceeded 24 hours, open fractures, flexion type fractures, Gartland type 1 and type 2 fractures, type T fractures, fractures with neurovascular deficit, multiple part fractures, pathological fracturs, patients with additional injuries and patients under the age of three year, were not included in the study since they would affect radiographicassessments.

Surgical decisions of the patients were made by the senior attending physician responsible from the emergency cases of that day, and they were operated by the same surgeon. All cases were operated under general anesthesia and in supine position. At first, closed reduction was applied to each case, and open reduction was applied in cases where sufficient reduction could not be achieved. In cases with closed reduction application, reduction was achieved under fluoroscopy; afterwards, percutaneous fixation was achieved with Kircshner wires (K-wires) according to the surgeon's preference. While a person ensures the continuity of the reduction, the pin was applied from the medial and/or lateral condylar sides by the surgeon. When the medial pin was applied, K-wire was inserted with a mini open surgery.

Unless the desired reduction could be achieved after 3 to 5 closed reduction attempts, open reduction was done. In cases where open reduction was done, one of the single lateral, single medial, lateral + medial double incision or posterior incision methods was used according to the surgeon's choice. Subsequently, percutaneous fixation was achieved with K-wires, according to the surgeon's preference. In all cases, the proximal part of the wires was left out of the skin in order to avoid a second anesthesia application.

After surgery, a long arm splint cast was applied to each patient. If postoperative roentgenograms were normal, finger exercises were explained to the patients and their discharge was planned after swelling follow-up for 24 hours. After three weeks, they were called to the first outpatient clinic, direct radiographies were scanned, the splints were removed, and passive ROM exercises wereallowed. Afterwards, 10 days of follow-up was ensured with outpatient clinic, and K-wires of cases with union findings upon radiological and physical examination were removed under outpatient clinic conditions. Deformity measurements were made on roentgenograms taken one month after the removal of K-wires.
The angle between lateral humeral condylar physis and humerus shaft was measured for Baumann angle. ${ }^{9} \mathrm{~A}$ range between $45^{\circ}$ and $57^{\circ}$ was accepted normal for lateral capito-humeral angle. ${ }^{10}$ As stated by Singh et al., thickness difference between both cortexes of proximal and distal fragments in anteroposterior and lateral elbow radiographies were assessed as rotations, and measured in milimeters. According to the rotation in the coronal plane of the distal piece measured in millimeters, the degree of the accepted rotation was grouped under three categories. Values between 0-2 mm were assessed as good, values between $3-5 \mathrm{~mm}$ were moderate, and values exceeding $5 \mathrm{~mm}$ were considered bad. ${ }^{11}$

In AP radiography, TEL was drawn with the line connecting middle points of lateral and medial epicondyles. Fracture line was assessed as bottom located, if one or two edges of the fracture line remains below this line; and as top located, if both ends of the fracture line were above the TEL. One side of the fracture line remaining below the epicondyle level may mean that the collateral ligament stuck on that epicondyle is independent from distal fracture fragment, and deformation of ligamentotaxis during closed reduction may mean that reduction has become difficult. For this reason, fracture line level was accepted as bottom in cases where any side of the fracture line remained below the TEL (Figure 1). 12,13

TEL was drawn with the line connecting middle points of lateral and medial epicondyles in AP radiographies. If there is no epicondylar ossification centre, the TEL was determined in a way to connect the most medial and lateral bone points adjacent to the epicondyle as performed by Bloom etal. (Figure2). ${ }^{14}$

Measures of the fracture line according to TEL were made from preoperative roentgenograms. Preoperative and postoperative radiographic measures were taken by imaging software used in the hospital named INFINITTPACS (Picture Archiving and Communication Systems) version 3.0.11.4 (BN13). Averages were taken after the measurements were taken by the only surgeon, who did not perform the operations. Numerical values, identified based on these measures, were used in statistical calculations as data. Surgeries were performed by ten different senior surgeons. All of the surgeons had over five years of experience in trauma surgery field.

Age, gender, surgery type (open/closed), Baumann angle, lateral capito-humeral angle, presence of postoperative rotation, localisation of fracture line according to TEL, surgery duration, postoperative varus/valgus deformity, postoperative flexion-extension deformity, and the surgeon were noted and the data were statistically assessed.

Statistical analyses were performed with SPSS version 25.0 software. The descriptiveanalyses were presented using mean, standard deviation, median and interquartile range (IQR) values. The compliance of the variables with normal distribution was examined with histogram/graphs and the Kolmogorov-Smirnov test. The independent group t-test was used when evaluating the normally distributed (parametric) variables between the groups. 
Table I: Comparison of patients' characteristics according to trans-epicondylar level.

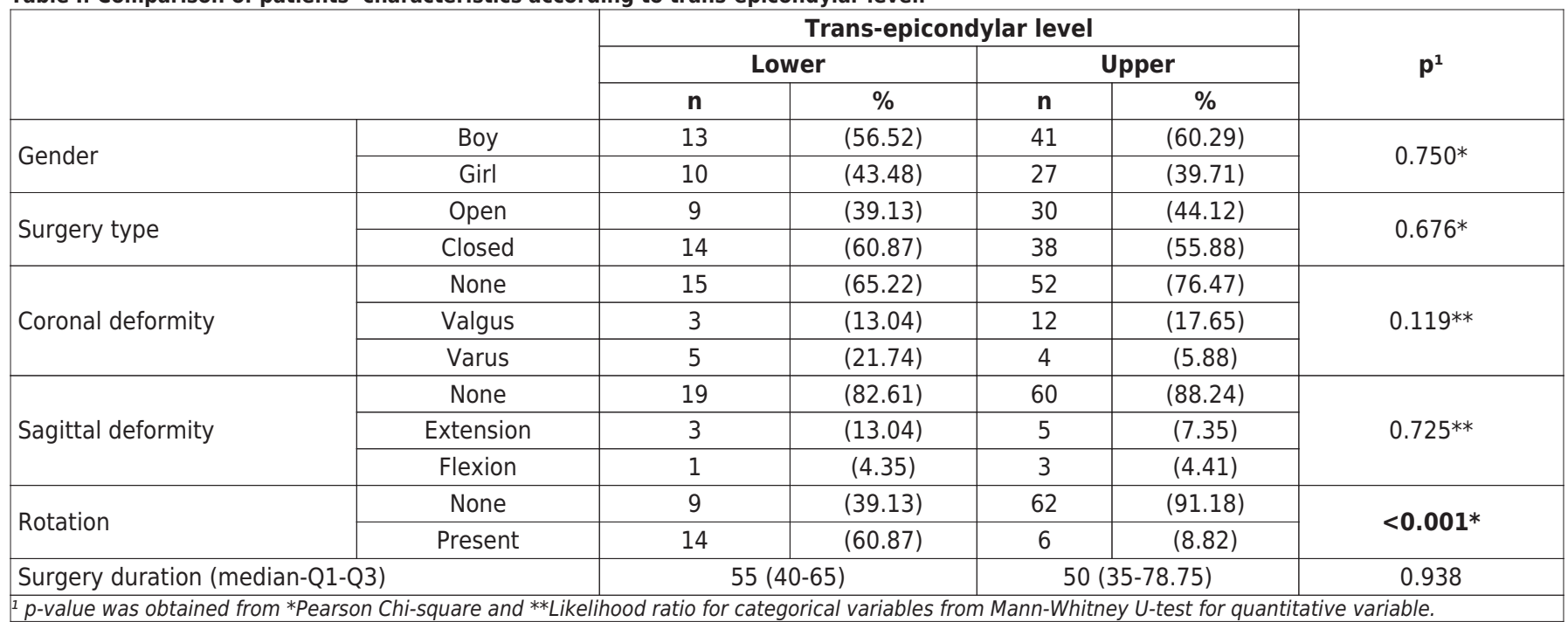

Table II: Comparison of patients' characteristics according to surgeons.

\begin{tabular}{|c|c|c|c|c|c|c|c|c|c|c|c|}
\hline & $\begin{array}{l}\text { Surgeon } \\
\# 1(n=8)\end{array}$ & $\begin{array}{c}\text { Surgeon } \\
\# 2(n=10)\end{array}$ & $\begin{array}{r}\text { Surgeon } \\
\# 3(n=7)\end{array}$ & $\begin{array}{c}\text { Surgeon } \\
\# 4(n=16)\end{array}$ & $\begin{array}{c}\text { Surgeon } \\
\# 5(n=8)\end{array}$ & $\begin{array}{l}\text { Surgeon } \\
\# 6(n=8)\end{array}$ & $\begin{array}{c}\text { Surgeon } \\
\# 7(n=11)\end{array}$ & $\begin{array}{l}\text { Surgeon } \\
\# 8(n=6)\end{array}$ & $\begin{array}{r}\text { Surgeon } \\
\# 9(n=9)\end{array}$ & $\begin{array}{c}\text { Surgeon } \\
\# 10(n=8)\end{array}$ & p-value \\
\hline Age (Median) & $4(2.5-6.5)$ & $4.5(4-7.25)$ & $6(3-10)$ & $7.5(4-10)$ & $3(2-4)$ & $6.5(5-9.75)$ & $7(5-9)$ & $6(2.5-10)$ & $7(6.5-8.5)$ & $5(4-9)$ & $0.088^{*}$ \\
\hline Surgery duration (Median) & $\begin{array}{c}55 \\
(27.5-71.25)\end{array}$ & $\begin{array}{c}77.5 \\
(50-97.5)\end{array}$ & $\begin{array}{c}75 \\
(50-105)\end{array}$ & $\begin{array}{c}47.5 \\
(35-60)\end{array}$ & $\begin{array}{c}42.5 \\
(32.5-58.75)\end{array}$ & $\begin{array}{c}45 \\
(35-112.5)\end{array}$ & $\begin{array}{c}40 \\
(30-45)\end{array}$ & $\begin{array}{c}45 \\
(40-72.5)\end{array}$ & $\begin{array}{c}35 \\
(27.5-50)\end{array}$ & $\begin{array}{c}65 \\
(41.25-91.25)\end{array}$ & $0.021 *$ \\
\hline $\begin{array}{l}\text { Sex } \\
\text { Girl } \\
\text { Boy }\end{array}$ & $\begin{array}{l}4(50 \%) \\
4(50 \%)\end{array}$ & $\begin{array}{l}6(60 \%) \\
4(40 \%)\end{array}$ & $\begin{array}{c}0(0 \%) \\
7(100 \%)\end{array}$ & $\begin{array}{l}9(56.2 \%) \\
7(43.8 \%)\end{array}$ & $\begin{array}{l}4(50 \%) \\
4(50 \%)\end{array}$ & $\begin{array}{l}4(50 \%) \\
4(50 \%)\end{array}$ & $\begin{array}{l}4(36.4 \%) \\
7(63.6 \%)\end{array}$ & $\begin{array}{l}2(33.3 \%) \\
4(66.7 \%)\end{array}$ & $\begin{array}{l}2(22.2 \%) \\
7(77.8 \%)\end{array}$ & $\begin{array}{l}4(50 \%) \\
4(50 \%)\end{array}$ & $0.236 * *$ \\
\hline $\begin{array}{l}\text { Surgery type } \\
\text { Closed } \\
\text { Open }\end{array}$ & $\begin{array}{l}4(50 \%) \\
4(50 \%)\end{array}$ & $\begin{array}{l}4(40 \%) \\
6(60 \%)\end{array}$ & $\begin{array}{l}2(28.6 \%) \\
5(71.4 \%)\end{array}$ & $\begin{array}{c}10(62.5 \%) \\
6(37.5 \%)\end{array}$ & $\begin{array}{c}8(100 \%) \\
0(0 \%)\end{array}$ & $\begin{array}{l}4(50 \%) \\
4(50 \%)\end{array}$ & $\begin{array}{l}9(81.8 \%) \\
2(18.2 \%)\end{array}$ & $\begin{array}{l}3(50 \%) \\
3(50 \%)\end{array}$ & $\begin{array}{l}6(66.7 \%) \\
3(33.3 \%)\end{array}$ & $\begin{array}{l}2(25 \%) \\
6(75 \%)\end{array}$ & $0.019 * *$ \\
\hline $\begin{array}{l}\text { Fracture Line } \\
\text { Lower } \\
\text { Upper }\end{array}$ & $\begin{array}{l}2(25 \%) \\
6(75 \%)\end{array}$ & $\begin{array}{l}1(10 \%) \\
9(90 \%)\end{array}$ & $\begin{array}{l}3(42.9 \%) \\
4(57.1 \%)\end{array}$ & $\begin{array}{l}7(43.8 \%) \\
9(56.2 \%)\end{array}$ & $\begin{array}{l}1(12.5 \%) \\
7(87.5 \%)\end{array}$ & $\begin{array}{c}0(0 \%) \\
8(100 \%)\end{array}$ & $\begin{array}{l}4(36.4 \%) \\
7(63.6 \%)\end{array}$ & $\begin{array}{l}2(33.3 \%) \\
4(66.7 \%)\end{array}$ & $\begin{array}{l}1(11.1 \%) \\
8(88.9 \%)\end{array}$ & $\begin{array}{l}2(25 \%) \\
6(75 \%)\end{array}$ & $0.185^{* *}$ \\
\hline $\begin{array}{l}\text { Coronal deformity } \\
\text { None } \\
\text { Varus } \\
\text { Valgus }\end{array}$ & $\begin{array}{l}6(75 \%) \\
0(0 \%) \\
2(25 \%)\end{array}$ & $\begin{array}{l}5(50 \%) \\
1(10 \%) \\
4(40 \%)\end{array}$ & $\begin{array}{l}3(42.9 \%) \\
3(42.9 \%) \\
1(14.3 \%)\end{array}$ & $\begin{array}{c}9(56.2 \%) \\
4(25 \%) \\
3(18.8 \%)\end{array}$ & $\begin{array}{c}5(62.5 \%) \\
1(12.5 \%) \\
2(25 \%)\end{array}$ & $\begin{array}{c}7(87.5 \%) \\
0(0 \%) \\
1(12.5 \%)\end{array}$ & $\begin{array}{c}10(90.9 \%) \\
0(0 \%) \\
1(9.1 \%)\end{array}$ & $\begin{array}{c}6(100 \%) \\
0(0 \%) \\
0(0 \%)\end{array}$ & $\begin{array}{c}8(88.9 \%) \\
0(0 \%) \\
1(11.1 \%)\end{array}$ & $\begin{array}{l}8(100 \%) \\
0(0 \%) \\
0(0 \%)\end{array}$ & $0.038^{* *}$ \\
\hline $\begin{array}{l}\text { Sagittal deformity } \\
\text { None } \\
\text { Flexion } \\
\text { Extension }\end{array}$ & $\begin{array}{c}8(100 \%) \\
0(0 \%) \\
0(0 \%)\end{array}$ & $\begin{array}{c}9(90 \%) \\
1(10 \%) \\
0(0 \%)\end{array}$ & $\begin{array}{c}6(85.7 \%) \\
0(0 \%) \\
1(14.3 \%)\end{array}$ & $\begin{array}{c}15(93.8 \%) \\
0(0 \%) \\
1(6.2 \%)\end{array}$ & $\begin{array}{c}7(87.5 \%) \\
0(0 \%) \\
1(12.5 \%)\end{array}$ & $\begin{array}{c}6(75 \%) \\
1(12.5 \%) \\
1(12.5 \%)\end{array}$ & $\begin{array}{c}9(81.8 \%) \\
0(0 \%) \\
2(18.2 \%)\end{array}$ & $\begin{array}{c}5(83.3 \%) \\
0(0 \%) \\
1(16.7 \%)\end{array}$ & $\begin{array}{c}7(77.8 \%) \\
2(22.2 \%) \\
0(0 \%)\end{array}$ & $\begin{array}{c}7(87.5 \%) \\
0(0 \%) \\
1(12.5 \%)\end{array}$ & $0.501 * *$ \\
\hline $\begin{array}{l}\text { Rotational deformity } \\
\text { None } \\
\text { Present }\end{array}$ & $\begin{array}{c}8(100 \%) \\
0(0 \%)\end{array}$ & $\begin{array}{l}9(90 \%) \\
1(10 \%)\end{array}$ & $\begin{array}{l}4(57.1 \%) \\
3(42.9 \%)\end{array}$ & $\begin{array}{l}8(50 \%) \\
8(50 \%)\end{array}$ & $\begin{array}{l}5(62.5 \%) \\
3(37.5 \%)\end{array}$ & $\begin{array}{c}8(100 \%) \\
0(0 \%)\end{array}$ & $\begin{array}{l}8(72.7 \%) \\
3(27.3 \%)\end{array}$ & $\begin{array}{l}5(83.3 \%) \\
1(16.7 \%)\end{array}$ & $\begin{array}{c}9(100 \%) \\
0(0 \%)\end{array}$ & $\begin{array}{l}7(87.5 \%) \\
1(12.5 \%)\end{array}$ & $0.007^{* *}$ \\
\hline
\end{tabular}

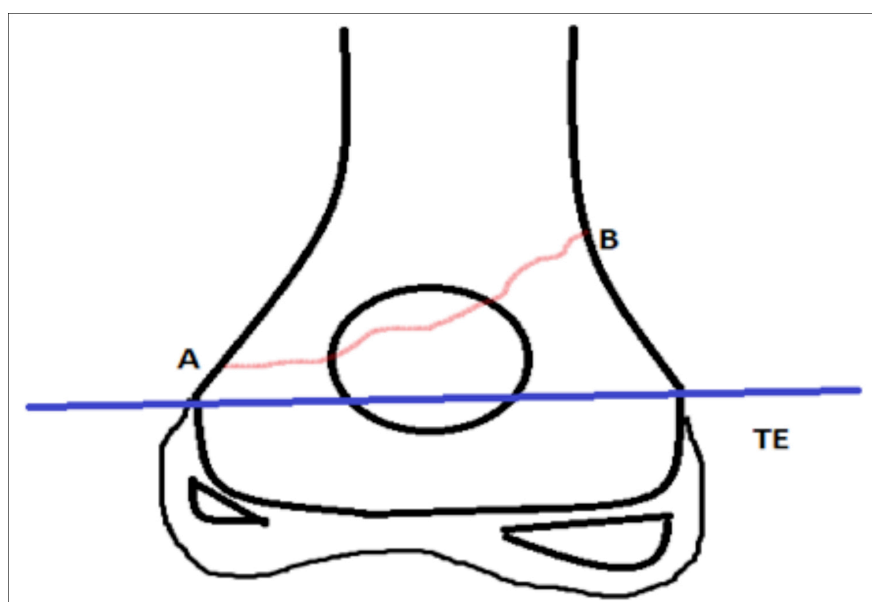

Figure 1: In AP radiography, the line connecting both epicondyles is determined as trans-epicondylar line. It was assessed as top, if both fracture line ends ( $A$ and B) are on this line, and as bottom if one or both are on the level below.

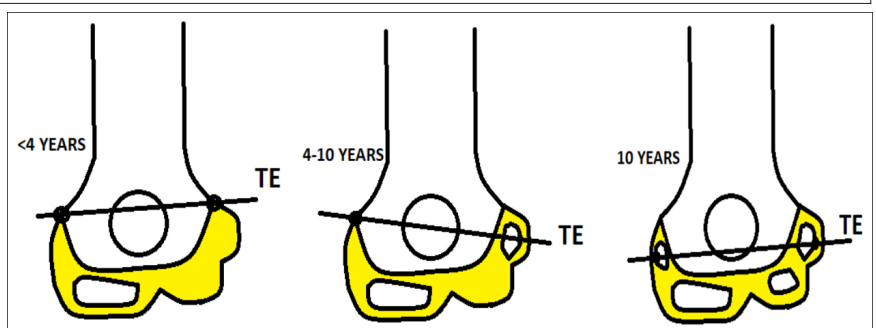

Figure 2: Appearance of ossification centres of orthopedic distal humerus according to ages and drawing of trans-epicondylar line. Trans-epicondylar line was drawn by connecting the lateral-medial ossified points in the nearest area to epicondyles in the anteroposterior radiography, according to ossified areas in the radiography. Drawing of trans-epicondylar lines, according to ages, are shown above (yellow area: non-ossified area of the distal humerus, which is not observed in radiographies).

Mann-Whitney U-test and Kruskal-Wallis H-test were used when evaluating the non-normally distributed (non-parametric) variables between the groups. Chi-square and Likelihood ratio tests were used when evaluating the categorical data. Cases where $p$-value was under 0.05 were found as statistically significant. 


\section{RESULTS}

Fifty-four boys (59.34\%) and 37 girls (40.66\%) cases were included in the study. Average age was $6.19 \pm 3.02$ years. The median duration time of surgery was 50 (IQR:40). Open reduction was applied to $39(42.86 \%)$ patients. The median of Baumann angle was 70 degrees (IQR:9) while the lateral capito-humeral angle median was 61 degrees (IQR:16). Twenty patients $(21.98 \%)$ had postoperative rotation. Upon measurement of patients with rotation, 8 (40\%) of them were assessed as good, 5 (25\%) of them were moderate, and 7 (35\%) of them were bad.

Nine patients $(9.89 \%)$ had varus deformity and 15 patients (16.48\%) had valgus deformity postoperatively. Valgus rate of closed reduction 13 patients (25\%) was higher compared to open reduction of two patients $(5.13 \%, p=0.039)$. Four patients $(4.4 \%)$ had flexion deformity and eight patients $(8.79 \%)$ had extension deformity in the postoperative period. According to TEL, fracture line passed through upper level of the line in $68(74.73 \%)$ cases, while it passed through lower level in 23 (25.27\%) cases. Rotation rate of 14 patients, whose fraction line localisation was lower according to TEL $(60.87 \%)$, was higher than upper localisation of six patients $(8.82 \%, p<0.001)$. The median of Baumann angle value of patients whose fraction line localisation was upper according to TEL 70 (IQR: 10) was lower than patients whose fraction line localisation was lower 73 (IQR: 13) $(p=0.05)$. It has been observed that the relation between localisation of fracture line according to TEL and sagittal deformity, coronal deformity, reduction type and surgery durations, were similar ( $p>0.05$, Table I).

Cases were operated by 10 different surgeons. No significance was present between surgeons in terms of sagittal deformities $(p=0.501)$. On the other hand, there was statistical significance present between surgeons in terms of surgery type $(p=0.019)$, presence of postoperative rotation $(p=0.007)$, coronal deformities $(p=0.038)$, and surgery durations $(p=0.021$, Table II).

\section{DISCUSSION}

Restoration of the fracture by anatomical reduction after closed reduction and percutaneous pinning in SHF is related with full range of motion of the joint and low complication rates. ${ }^{3}$ An aggressive approach for accurate reduction and stabilisation of these fractures is related with low incidence of long-term deformities. ${ }^{15}$ Open reduction is applied in cases where closed reduction is unsuccessful, and open reduction is associated with increasing complication rates such as elbow hardness, scar, iatrogenic neurovascular damage, myositis ossificans, longer hospitalisation, and higher infection risks. ${ }^{16}$ At the same time, approach of the surgeon performing the operation for these fractures can also be effective on open surgery rates. ${ }^{17-19}$ There was no association between localisation of the fracture line according to TEL and open reduction rates. On the other hand, there was a relation between surgeons and open reduction rates. As stated in the literature, this condition may be associated with the array obtained after closed reduction and decision of the surgeon in relation to this surgery.

Singh et al. has reported that post-reduction rotation constitutes more importance in orthopedic elbow fractures; however, it has very little effect on function. ${ }^{11}$ Aiyer et al. have suggested that it causes very little deformation since the rotation is compensated by shoulder joint. ${ }^{20}$ In this study, rotation rates were higher in cases where the fracture line passed below the TEL; the ligamentotaxis provided by the position of the forearm during pin fixation constitutes importance in the continuance of distal fragment reduction even if open reduction is performed in supracondylar fractures. The increase in rotation frequency in cases where the fracture line is below the TEL, may depend on this condition.

It is not important to accurately localise the fracture surfaces in pediatric age group. This has little effect on final range of motion and carrying angle. The final remodelisation tolerates many faults. ${ }^{21}$ However, rotation deformities are not expected to be corrected with remodelisation. ${ }^{22}$ The rotation observed after reduction causes medial angulation. Although rotation alone does not cause cubitus varus, it may cause misalignment of varus. ${ }^{11,23}$

In cases where the fracture line is lower than the TEL, Baumann angles also had higher values besides rotation. This may be the result of the rotation causing medial angulation. On the other hand, the authors believe that the rotation must be corrected anatomically during the reduction of pediatric fractures, since the remodeling of the rotation does not recover. Because functional or cosmetic problems, which occur as a result of this rotation, will also bring postoperative dissatisfaction and additional surgical interventions. Determining the localisation of the fracture line, according to the trans-epicondylar line, may allow the surgeon to predict during the preoperative period and provide warnings to be more cautious during surgery.

Personal characteristics of the surgeon are effective on postoperative malalignment rates in surgeries of SHF. ${ }^{17-19}$ There was a relation between rotation rates and surgeons in this study. In this case, it would not be sufficient to predict the rotation possibility by determining the fracture line, according to TEL only. From another perspective, if postoperative rotation rates are affected from the surgery, it would cause the surgeon to be cautious during the surgery, if he/she is aware of this possibility in the preoperative period. This may even cause a decrease in rotation rates depending on the surgeon.

Limitations of this study are retrospective, multiple surgeons performing the surgery, and it does not provide information on functional and cosmetic results. Other limitation is the lack of knowledge about bone alignment of the numerical 
values, measured in the long run, and ranges of motion of the elbow.

\section{CONCLUSION}

Determination of localisation of fracture line, according to trans-epicondylar level in preoperative roentgenograms, may allow the surgeon to predict the possibility of postoperative rotation deformity. This can provide warnings for the surgeon to be more cautious during the operation.

\section{ETHICAL APPROVAL:}

The study was approved from Ethical Review Committee of University of Health Sciences, Okmeydanı Training and Research Hospital, Istanbul, Turkey.

\section{PATIENTS' CONSENT:}

Written informed consents were obtained from study participants.

\section{CONFLICT OF INTEREST:}

Authors declared no conflict of interest.

\section{AUTHORS' CONTRIBUTION:}

AY: Idea conception, data collection, data analysis, results, discussion and literature review.

CDB Data analysis and results writing.

BK: Idea conception, data analysis, results, discussion and literature review.

AÖ: Data collection and literature review.

MY: Review of article and discussion.

HG: Discussion and literature review.

\section{REFERENCES}

1. Prashant K, Lakhotia D, Bhattacharyya TD, Mahanta AK, Ravoof A. A comparative study of two percutaneous pinning techniques (lateral vs medial-lateral) for Gartland type III pediatric supracondylar fracture of the humerus. J Orthopaed Traomatol 2016; 17(3):223-9. doi: 10.1007/ s10195-016-0410-2.

2. Morrison SA, Pincus D, Camp MW. Complication of type II supracondylar humerus fractures treated at a specialised paediatric centre. Paediatr Child Health 2020; 25(4): 228-34. doi: 10.1093/pch/pxy167.

3. Abzug JM, Herman MJ. Management of supracondylar humerus fractures in children: Current concepts. J Am Acad Orthop Surg 2012; 20(2):69-77. doi: 10.5435/JAAOS20-02-069.

4. Holland P, Highcock A, Bruce C. Distance of translation as a predictor of failure of fixation in paediatric supracondylar fractures. Ann R Coll Surg Engl 2017; 99(7):524-8. doi: 10.1308/rcsann.2017.0040.

5. Fayssoux RS, Stankovits L, Domzalski ME, Guille JT. Fractures of the distal humeral metaphyseal-diaphyseal junction in children. J Pediatr Orthop 2008; 28(2):142-6. doi: 10.1097/BPO.0b013e3181653af3.

6. Camp CL, Fu M, Jahandar H, Desai VS, Sinatro AM, Altchek $\mathrm{DW}$, et al. The lateral collateral ligament complex of the elbow: quantitative anatomic analysis of the lateral ulnar collateral, radial collateral, and annular ligaments. J Shoulder Elbow Surg 2019; 28(4):665-70. doi: 10.1016/ j.jse.2018.09.019.

7. Bogdan A, Quintin J, Schuind F. Treatment of displaced supracondylar humeral fractures in children by humeroulnar external fixation. Int Orthop 2016; 40(11):2409-15. doi: 10.1007/s00264-016-3251-y.

8. Bégué T. Articular fractures of the distal humerus. Orthop Traumatol Surg Res 2014; 100(1 Suppl):55-63.

9. Kitta MI, Ismiarto YD, Saleh MR, Sakti M, Abidin MA, Putra LT. Analysis of radiological alignment and functional outcomes of pediatric patients after surgery with displaced supracondylar humerus fracture: A cross-sectional study. Int J Surg Open 2020; 24:136-42.

10. Tuomilehto N, Kivisaari R, Sommarhem A, Nietosvaara AY. Outcome after pin fixation of supracondylar humerus fractures in children: Postoperative radiographic examinations are unnecessary A retrospective study of 252 Gartland-III and 12 flexion-type supracondylar humerus fractures. Acta Orthopaedica 2017; 88(1):109-15. doi: 10.1080/1745 3674.2016.1250058.

11. Singh I, Rupabati Devi RK, Sharma GS. A prospective study of supracondylar fractures of the humerus in children treated by closed reduction. J Evidence Based Med Healthcare 2015; 2(33):4958-67.

12. Moradi A, Vahedi E, Ebrahimzadeh MH. Surgical technique: Spike translation: A new modification in step-cut osteotomy for cubitis varus deformity. Clin Orthop Relat Res 2013; 471(5):1564-71. doi: 10.1007/s11999-012-2756-y.

13. Shiba R, Sorbie C, Siu DW, Bryant JT, V. Cooke TD, Wevers HW. Geometry of the humeroulnar joint. J Orthop Res 1988; 6(6):897-906. doi: 10.1002/jor.1100060614.

14. Bloom T, Zhao C, Mehta A, Thakur U, Koerner J, Sabharwal S. Safe zone for superolateral entry pin into the distal humerus in children: An MRI Analysis. Clin Orthop Relat Res 2014; 472(12):3779-88. doi: 10.1007/s11999-014-3509-x.

15. Mangwani J, Nadarajah R, Paterson JMH. Supracondylar humeral fractures in children ten years' experience in a teaching hospital. J Bone Joint Surg Br 2006; 88(3):362-5. doi: 10.1302/0301-620X.88B3.16425.

16. Büyükkurt CD, Yerli M, Dedeoğlu SS, İmren Y, Kır MÇ, Tekin AÇ. The effect of surgical timing on the outcomes of pediatric Gartland Type III supracondylar humeral fractures. Eur Arc Med Res 2020; 36(3):178-82.

17. Dodds SD, Grey MA, Bohl DD, Mahoney EM, Deluca PA. Clinical and radiographic outcomes of supracondylar humerus fractures treated surgically by pediatric and non-pediatric orthopedic surgeons. J Child Orthop 2015; 9(1):45-53. doi: 10.1007/s11832-015-0642-3.

18. DeFrancesco CJ, Shah AS, Brusalis CM, Flynn K, Leddy K, Flynn JM. Rate of open reduction for supracondylar humerus fractures varies across pediatric orthopaedic surgeons: A single-Institution analysis. J OrthopTrauma 2018 Oct; 32(10): e400-7. doi: 10.1097/BOT.0000000000001262.

19. Pesenti S, Ecalle A, Peltier E, Choufani E, Blondel B, Jouve J, et al. Experience and volume are determinantive factors for operative management of supracondylar humeral fractures in children. J Shoulder Elbow Surg 2018; 27(3):404-10. doi: 
10.1016/j.jse.2017.10.014.

20. Aiyer S, Naskar R, Raja BS, Manghwani J, Khairnar G, Bindumadhavan S. Incidence of residual varus deformity in operated cases of supracondylar humerus fracture in children. Int J Orthopaedics Sci 2017; 3(4):153-9. doi.org/10.22271/ ortho.2017.v3.i4c.22.

21. Brubacher JW, Seth DD. Pediatric supracondylar fractures of the distal humerus. Curr Rev Musculoskel Med 2008;
1(3-4):190-6. doi: 10.1007/s12178-008-9027-2

22. Davids JR. Rotational deformity and remodeling after fracture of the femur in children. Clin Orthop Relat Res 1994; (302):27-35.

23. Mounsey EJ, Howard A. Evidence-based treatments of paediatric elbow fractures. In: Alshryda S, Huntley J, Banaszkiewicz P, Eds. Paediatric Orthopaedics. ed. 1st, Springer; Cham; 2017: p.305-15. 